\title{
Pelletization performance of Panzhihua ilmenite concentrate
}

\author{
Bing Song ${ }^{1,2^{*}}$, Ping Huang ${ }^{3}$, Yong $\mathrm{Ma}^{4}$, Zan Song ${ }^{5}$, and Zhake $\mathrm{He}^{4}$ \\ ${ }^{1}$ Pangang Group Research Institute Co.Ltd. , Panzhihua, 617000, Sichuan, China \\ ${ }^{2}$ State Key Laboratory of Vanadium and Titanium Resources Comprehensive Utilization. Panzhihua, \\ 617000, Sichuan, China \\ ${ }^{3}$ Panxi Science and Technology Innovation Center, Panzhihua University, 617000, Sichuan, China \\ ${ }^{4}$ Pangang Group Vanadium Titania \& Resources Co. Ltd., Panzhihua, 617000, Sichuan, China \\ ${ }^{5}$ Metallurgical Center for International Exchange and Cooperation. Beijing, 100711, China
}

\begin{abstract}
The influences of particle size distribution and the binder on the pelletization performance of Panzhihua ilmenite concentrate were studied in this paper. The results showed that the particle size distribution of Panzhihua ilmenite concentrate has the most important on its pelletization. The particle size distribution of ilmenite concentrate was significant changed and the specific surface area increased after grinding. The particle size of $45 \mu \mathrm{m}$ should be controlled less than $55 \%$ and $74 \mu \mathrm{m}$ no more than $74 \%$ in order to acquire a better performance of pellets. While the same performance of pellets can be obtained when the specific surface area of ilmenite concentrate was $1493 \mathrm{~cm} 2 / \mathrm{g}$. The performance of pellets added with an organic binder is better than added bentonite. The pellet's performance could be further improved under the mixed ratio of $1.05 \%$ bentonite and $0.45 \%$ organic binder.
\end{abstract}

\section{Introduction}

The development of titanium industry requires large number of high quality titanium ore. Although natural rutile and titanium mineral were main raw material to titanium industry, the resources decreased worldwide. The low grade titaniferrous ores such as ilmenite should be paid more attention. Titania slag prepared by smelting of ilmenite in an electric arc furnace (EAF) can be served as a superior quality raw materials containing titanium to the pigment or other titanium products industrial processes[1]. Therefore, titania slag is the key to improve the comprehensive utilization level of titanium resources. However, particle size of Panzhihua ilmenite concentrate has become more and more fine. Using these fine ilmenite concentrate directly to smelt, some problems would appear, such as pollution environment, decreasing of the smelting stability and increasing of the smelting cost[2]. Therefore, pelletizing is necessary to using the fine ore[3].

The possible technical routes for treating Panzhihua fine ilmenite concentrate can be classified into two methods, namely, briquetting and pelletizing. Han [3] studied on the effect of mixing time, pressure, binder and rotational speed on compressive strength of

*Corresponding author: sdbingsongbing@163.com 
pellets. Ren[4] reported on the effect of grinding time, binder and drying temperature on pelleting of Panzhihua fine ilmenite concentrate. But they did not consider the effect of particle size distribution. There are few studies on pelletization performance of Panzhihua ilmenite concentrate in the literature.

The purpose of this present investigation was to study the effect of particle size distribution and binder on the pelletizing of ilmenite concentrate, while, obtaining a better parameter to improvement pelletization performance of Panzhihua ilmenite concentrate.

\section{Experimental}

\subsection{Raw materials}

The chemical composition of ilmenite concentrate is listed in Table 1. Bentonite and the organic binder were employed as a binder and its chemical composition is given in Table 2.

Table 1. Chemical composition of ilmenite concentrate (wt.\%).

\begin{tabular}{|c|c|c|c|c|c|c|c|c|}
\hline Ilmenite concentrate & $\mathrm{TiO}_{2}$ & $\mathrm{FeO}$ & $\mathrm{Fe}_{2} \mathrm{O}_{3}$ & $\mathrm{CaO}$ & $\mathrm{MgO}$ & $\mathrm{SiO}_{2}$ & $\mathrm{Al}_{2} \mathrm{O}_{3}$ & $\mathrm{~S}$ \\
\hline $\mathrm{A}$ & 47.80 & 35.91 & 4.89 & 0.87 & 5.18 & 3.08 & 1.24 & 0.15 \\
\hline $\mathrm{B}$ & 48.18 & 35.91 & 4.89 & 0.59 & 5.64 & 2.72 & 1.00 & 0.10 \\
\hline $\mathrm{C}$ & 46.76 & 34.95 & 6.55 & 0.75 & 4.86 & 2.86 & 2.01 & 0.27 \\
\hline
\end{tabular}

Table 2. Chemical composition of binder (wt.\%).

\begin{tabular}{|c|c|c|c|c|c|c|c|}
\hline Binder & $\mathrm{C}$ & $\mathrm{Na}_{2} \mathrm{O}$ & $\mathrm{Fe}_{2} \mathrm{O}_{3}$ & $\mathrm{CaO}$ & $\mathrm{MgO}$ & $\mathrm{SiO}_{2}$ & $\mathrm{Al}_{2} \mathrm{O}_{3}$ \\
\hline Bentonite & 0.29 & 1.48 & 1.77 & 2.24 & 2.90 & 48.66 & 12.95 \\
\hline Organic binder & 12.30 & 10.40 & 1.00 & 2.69 & 14.56 & 9.13 & 2.78 \\
\hline
\end{tabular}

\subsection{Experimental apparatus and methods}

A disk pelletizer was employed to acquire pellets. The schematic diagram of pelletizer is shown in Figure 1. The pelletizing flow chart of ilmenite concentrate is shown in Figure 2.

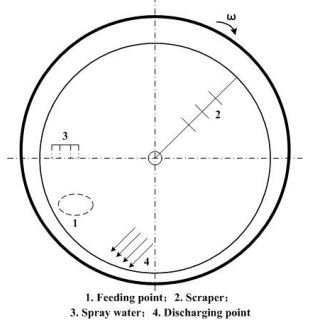

Fig. 1. Schematic diagram of pelletizer.

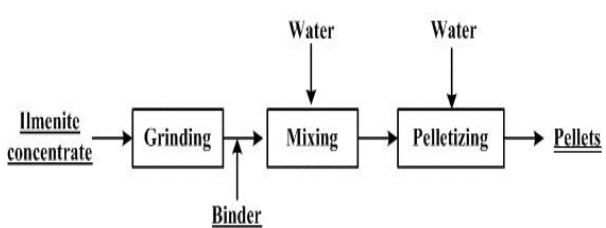

Fig. 2. Flow chart of pelletizing.

$50 \mathrm{~g}$ of sample was screened with $45 \mu \mathrm{m}$ and $74 \mu \mathrm{m}$ set sieve. Screened sample was dried $2 \mathrm{~h}$ at $393 \mathrm{~K}$ and then weighed. Scanning electron microscope (SEM, JSM-5600LV, Japan) was employed to study the ilmenite concentrate particle surface morphology. Specific surface area of ilmenite concentrate was determined using liquid nitrogen adsorption method in the automatic surface area analyzer (GEMINI VII 2390, USA).

$5000 \mathrm{~g}$ ilmenite concentrate with a certain amount of binder was pelletized which is 8 to $12 \mathrm{~mm}$ in diameter. The average value of compressive strength and drop strength was used as the performance criterion of ilmenite concentrate pellets[5,6]. The compressive strengths of pellets was messured using a compression strength tester (HXQT-10D, China). The drop strengths of pellet is the free falling time from 0.5 meters height until the pellets break. The standard indicators of ilmenite concentrate pellets are more than $800 \mathrm{~g}$ to the compressive strength and more than 6 times to the drop strength according to the previous literature [5]. 


\section{Results and discussion}

\subsection{Effect of particle size distribution}

Ilmenite concentrates D, E, and F is obtained after the grinding of A, B, and C, respectively. Particle size distribution of concentrates used in the tests is shown in Table 3.

The binder content is $1.5 \%$ in each mixtures. A better pelletization performance can be acquired when the content of ilmenite concentrate particle size $-74 \mu \mathrm{m}$ more than $85 \%$ during the production process of pellets from our previous research. Therefore, ilmenite concentrate $\mathrm{E}$ maybe a better raw material to produce a pellet according to the particle size distribution [7]. The $-74 \mu \mathrm{m}$ content in ilmenite concentrate $\mathrm{A}$ is only $51.84 \%$. The results indicated that the ilmenite concentrate pelleting needs Fine particle size and binder. Compared with ilmenite concentrate A, ilmenite concentrate D is not only particle size significantly fine but also the compressive strength and drop strength increased $416 \mathrm{~g}$ and 4.7 times, respectively. It is indicated that the particle size of ilmenite concentrate is reduced can improve the pelletization performance.

Drop strength of pellets was reduced, and the compressive strength of pellets without significantly increased with decreased the particle size from E and F. This result strongly suggests that the smaller ilmenite is not obviously helping to improve performance. Therefore, the strength of pellets does not necessarily significantly improved via to reduce the particle size of ilmenite concentrate. Ilmenite concentrate needs to have a suitable particle size. The results are consistent with those reported in the literature [8].

Table 3. Particle size distribution of ilmenite concentrate/wt.\%.

\begin{tabular}{|c|c|c|}
\hline \multirow{2}{*}{$\begin{array}{c}\text { Ilmenite } \\
\text { concentrate }\end{array}$} & \multicolumn{2}{|c|}{ Particle size distribution } \\
\cline { 2 - 3 } & $-74 \mu \mathrm{m}$ & $-45 \mu \mathrm{m}$ \\
\hline $\mathrm{A}$ & 51.84 & 24.68 \\
\hline $\mathrm{B}$ & 77.74 & 43.22 \\
\hline $\mathrm{C}$ & 54.60 & 28.54 \\
\hline $\mathrm{D}$ & 71.36 & 46.84 \\
\hline $\mathrm{E}$ & 98.65 & 85.90 \\
\hline F & 76.10 & 53.90 \\
\hline
\end{tabular}

Table 4. Average performance of pellets.

\begin{tabular}{|c|c|c|}
\hline $\begin{array}{c}\text { Ilmenite } \\
\text { concentrate }\end{array}$ & $\begin{array}{c}\text { Compressio } \\
\text { n strength/g }\end{array}$ & $\begin{array}{c}\text { Drop } \\
\text { strength/times }\end{array}$ \\
\hline $\mathrm{A}$ & - & - \\
\hline $\mathrm{B}$ & 465 & 5.1 \\
\hline $\mathrm{C}$ & 683 & 6.4 \\
\hline $\mathrm{D}$ & 416 & 4.7 \\
\hline $\mathrm{E}$ & 1170 & 4.8 \\
\hline $\mathrm{F}$ & 490 & 5.0 \\
\hline & & \\
\hline
\end{tabular}

Fig. 3. Arrangement of ilmentie concentrate particle.

Figure 4 shows that the performances of all the pellets which were prepared using single ilmenite concentrate cannot meet the production requirements. Ilmenite concentrate $\mathrm{C}$ and E was carried out according to a certain ratio to study the pelletization performance of ilmenite. The ratio of raw material and indexes of pellets are shown in table 5 and table 6 , respectively. 
The average diameter of the capillary is reduced and the inter-particle binding force is increased, as shown in figure 3. Figure 3 (a) shows that the relatively uniform particle size could increase the porosity. Therefore, a suitable particle size composition is required to improve the strength of ilmenite concentrate pellets [9].

Table 5. Raw material ratio and particle size of distribution of ilmenite concentrate /wt. \%.

\begin{tabular}{|c|c|c|c|c|c|}
\hline \multirow{2}{*}{ No } & \multicolumn{2}{|c|}{$\begin{array}{l}\text { Ilmenite } \\
\text { concentrate }\end{array}$} & \multirow{2}{*}{$\begin{array}{c}\text { Binder } \\
/ \%\end{array}$} & \multicolumn{2}{|c|}{ Particle size distribution } \\
\hline & $\mathrm{C}$ & $\mathrm{E}$ & & $-74 \mu \mathrm{m}$ & $-45 \mu \mathrm{m}$ \\
\hline 1 & 75 & 25 & 1.5 & 62.28 & 40.47 \\
\hline 2 & 50 & 50 & 1.5 & 74.09 & 54.57 \\
\hline 3 & 25 & 75 & 1.5 & 85.9 & 68.66 \\
\hline
\end{tabular}

Table 6. Average performance of pellets.

\begin{tabular}{|c|c|c|}
\hline No. & $\begin{array}{c}\text { Compression } \\
\text { strength/g }\end{array}$ & Drop strength/times \\
\hline 1 & 789 & 4.2 \\
\hline 2 & 872 & 6.4 \\
\hline 3 & 1070 & 8.4 \\
\hline
\end{tabular}

\subsection{Effect of the surface area}

Some literature has pointed out that there is a linear relationship between the compressive strength and the specific surface area of pellets. Many researchers also use the specific surface area to measure the particle size of material.

The specific surface area of ilmenite concentrate B after grinding as show in figure 4 . Figure 4 demonstrates that the specific surface area of ilmenite concentrate is increased with increasing the content of particle size less than $45 \mu \mathrm{m}$ from $40 \%$ to $80 \%$. The particle size of ilmenite concentrate and surface area has a significant positive correlation.

Compressive strength and drop strength of obtained pellets from titanium concentrate $B$ with different specific surface areas is shown in figure 5. Compressive strength and drop strength of pellets is increasing with the increase the specific surface area. It is indicated that the contact surface of particles was increased each other during the pelletization processing if the surface area of ilmenite concentrate larger. The strength of pellets was further increased. The produced pellets can be directly used in industrial production when the specific surface area of ilmenite concentrate reach $1493 \mathrm{~cm}^{2} / \mathrm{g}$. That is the content of particle size less than $45 \mu \mathrm{m}$ is about $70 \%$ in ilmenite concentrate.

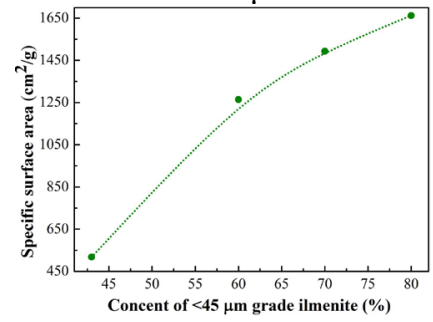

Fig. 4. Specific surface area of ilmenite concentrate $\mathrm{B}$ at different particle size.

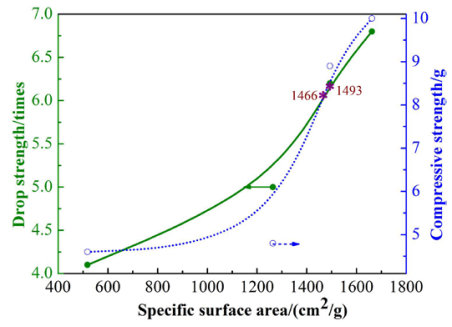

Fig. 5. Indexes of ilmenite concentrate B pellet at different surface area.

Particle microscopic morphology of ilmenite concentrate $\mathrm{C}$ is shown in Figure 6. Figure 6 (a) is ilmenite concentrate C; Ilmenite concentrate particles in (a), (b) and (c) are relatively regular in shape and have a dense and smooth surface. The particle shape of ilmenite concentrate is main long-sized in figure 6(C). The contact area of spherical particles is significantly less than long-sizes particles during the pelletization processing. Therefore, the particle size is reduced and the particle shape also changed after grinding of 
ilmenite concentrate and improved the pelletization performance of ilmenite concentrate.

Ilmenite concentrate which particle size less than $45 \mu \mathrm{m}$ reach $95 \%$ is so fine that the fine particles will adsorbed on the surfaces of larger particles to agglomerate. Agglomerate phenomenon of fine particle can be clearly observed in (e) or (f). Specific surface area of ilmenite concentrate will be decreased after agglomerate of particle. Specific surface area is directly determines the contact area between particles and also reflects the adhesion degree.
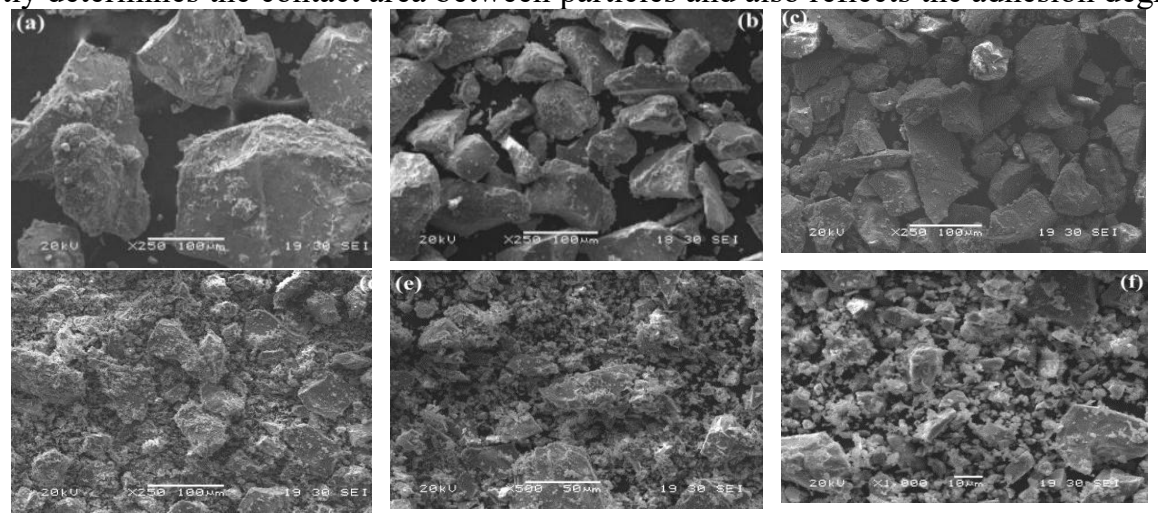

Fig. 6. Particle surface morphology of ilmenite concentrate C.((a)、(b)、 (c) and (d) is $250 \times$; (e) and (f) is $500 \times$ and $1000 \times$, respectively).

\subsection{Effect of binder}

\subsubsection{Organic binder}

Ratio of mixture of $50 \%$ ilmenite concentrate $\mathrm{C}$ and $\mathrm{E}$ with binders as shown in table 7 . Performances of pellets are shown in table 8. Compressive strength of pellets was decreased with increasing content of organic binder. Drop strength of pellets was reduced with decreasing the content of organic binder. Drop strength of pellets and moisture in pellet was increased with increasing organic binder content. Drop strength of $1^{\#}$ and $2^{\#}$ is without significantly difference. The better added content of organic binder could be controlled in $1.2 \%$ to meet performances of pellets and consider the cost of organic binder.

Table 7. Ratio of ilmenite and organic binder.

Table 8. Average performance of pellets.

\begin{tabular}{|c|c|c|c|}
\hline \multirow{2}{*}{ No } & \multicolumn{2}{|c|}{$\begin{array}{c}\text { Ilmenite } \\
\text { concentrate }\end{array}$} & \multirow{2}{*}{$\begin{array}{c}\text { Organic } \\
\text { binder }\end{array}$} \\
\hline & $\mathrm{C}$ & $\mathrm{E}$ & \\
\hline 1 & 50 & 50 & 1.5 \\
\hline 2 & 50 & 50 & 1.2 \\
\hline 3 & 50 & 50 & 0.9 \\
\hline
\end{tabular}

\begin{tabular}{|c|c|c|c|}
\hline $\begin{array}{c}\mathrm{N} \\
\mathrm{o}\end{array}$ & $\begin{array}{c}\text { Compressio } \\
\mathrm{n} \text { strength/g }\end{array}$ & $\begin{array}{c}\text { Drop } \\
\text { strength/tim } \\
\text { es }\end{array}$ & $\begin{array}{c}\text { Moisture } \\
/ \text { wt.\% }\end{array}$ \\
\cline { 1 - 3 } $1^{\#}$ & 872 & 6.4 & 9.48 \\
\hline $2^{\#}$ & 945 & 5.4 & 9.41 \\
\hline $3^{\#}$ & 959 & 3.2 & 8.53 \\
\hline
\end{tabular}

\subsubsection{Mixed binder}

The above results shows that pellets with only organic binder can meet the smelting conditions, but organic binder cost is higher. Although the price of bentonite is low, the performance of pellets with bentonite poor. The mixed binder of organic binder and bentonite was employed to improve the performance of pellets. The ratio of ilmenite concentrate and mixed binder as shown in table 9. The average performance of pellets is shown in table 10.

Compared with table 8 or table 10, the performance of pellets with an amount of mixed 
binder are better than a single binder. It is indicated that the mixed binder is helping to improve the pelletization performance. The better ratio of mixed binder is $1.05 \%$ organic binder and $0.45 \%$ bentonite.

Table 9. Ratio of ilmenite concentrate and mixed binder. Table 10. Average performance of pellets.

\begin{tabular}{|c|c|c|c|}
\hline \multirow{2}{*}{ No } & \multicolumn{2}{|c|}{$\begin{array}{c}\text { Ilmenite } \\
\text { concentrate }\end{array}$} & \multirow{2}{*}{$\begin{array}{c}\text { Organic } \\
\text { binder }\end{array}$} \\
\hline & $\mathrm{C}$ & $\mathrm{E}$ & \\
\hline 1 & $\mathrm{C}$ & $\mathrm{E}$ & 1.5 \\
\hline 2 & 50 & 50 & 1.2 \\
\hline 3 & 50 & 50 & 0.9 \\
\hline
\end{tabular}

\begin{tabular}{|c|c|c|c|}
\hline No & $\begin{array}{c}\text { Compressi } \\
\text { on } \\
\text { strength/g }\end{array}$ & $\begin{array}{c}\text { Drop } \\
\text { strength/ti } \\
\text { mes }\end{array}$ & $\begin{array}{c}\text { Moistur } \\
\mathrm{e}\end{array}$ \\
\hline 1 & 872 & 6.4 & 9.48 \\
\hline 2 & 945 & 5.4 & 9.41 \\
\hline 3 & 959 & 3.2 & 8.53 \\
\hline
\end{tabular}

\section{Conclusions}

1. Panzhihua fine ilmenite concentrate can be pelleted through controlled the particle size diatribution or added the binder. The better process parameters were obtained and the index of ilmenite concentrate pellets established.

2. Reduced particle size of ilmenite concentrate will improve pelletization performance during a certain range. Finer ilmenite concentrate mixed with a certain amount of coarser titanium concentrate is more conducive to pelleting. Particle size $-45 \mu \mathrm{m}$ content should be controlled at $55 \%$, or $-74 \mu \mathrm{m}$ at $74 \%$ in mixture of ilmenite concentrate.

3. The mixture binder of bentonite and organic binder can improve the performance of ilmenite concentrate pellets. The better ratio is $1.05 \%$ bentonite and $0.45 \%$ organic binder.

\section{References}

1. LYU X W, Song B, Han K X, Zhang K. Effect of ferrosilicon addition on direct reduction of ilmenite concentrate and Its separation between iron and slag [J]. Journal of Northeastern University (Natural Science), 2015, 36(2):223-226.

2. P, Pistorius and Coetzee C. Physicochemical aspects of titanium slag production and solidification [J]. Metallurgical and Materials Transactions B, 2003, 34 (5): 581 588.

3. Han K X. Study on granulation of fine grained ilmenite concentrate [J]. Panzhihua Sci\&Tech Information, 2011,36(4):52-56.

4. Ren C C. Pelletizing experimence of micro-fine grained ilmenite concentrate [J].Express Information of Mining Industry, 2001,(10):296-299.

5. Fu J Y, Jiang T, Zhu D Q. Sintering pelletization [M]. Changsha: Central South University of Technology Press, 1996.

6. P. chindaprasirt, S. Hatanaka and N. Mishima et. al. Effects of binder strength and aggregate size on the compressive strength and void ratio of porous concrete[J]. International Journal of Minerals Metallurgy and Materials.

7. $\mathrm{Hu} Z$ Q Q, Pan J, Zhu D Q, Yue S Y. Raw material characteristics of iron ore concentrate and its influence on balling performance [J]. Sintering and Pelletizing, 2013, 38(4):42-49.

8. Zhang Y X, Rao J T, He M G, Li Y H. Research on the suitable particle size of production pellets about vanadium titanium ore concentrate [J]. Sichuan Metallurgy, 2010,33(5):12-15.

9. Wang C A, Luo L M. The influence of pelletizing quality by using different size distribution of concentrate [J].Journal of Wuhan Institute of Chemical Technology, 2005,27(2):38-41. 